\title{
Characteristics of monsoon inversions over the Arabian Sea observed by satellite sounder and reanalysis data sets
}

\author{
Sanjeev Dwivedi ${ }^{1}$, M. S. Narayanan ${ }^{1}$, M. Venkat Ratnam ${ }^{2}$, and D. Narayana Rao ${ }^{1}$ \\ ${ }^{1}$ Department of Physics, SRM University, Kattankulathur, Chennai, India \\ ${ }^{2}$ National Atmospheric Research Laboratory (NARL), Gadanki, Tirupati, India \\ Correspondence to: M. Venkat Ratnam (vratnam@narl.gov.in)
}

Received: 14 September 2015 - Published in Atmos. Chem. Phys. Discuss.: 15 December 2015

Revised: 6 March 2016 - Accepted: 22 March 2016 - Published: 12 April 2016

\begin{abstract}
Monsoon inversion (MI) over the Arabian Sea (AS) is one of the important characteristics associated with the monsoon activity over Indian region during summer monsoon season. In the present study, we have used 5 years (2009-2013) of temperature and water vapour measurement data obtained from satellite sounder instrument, an Infrared Atmospheric Sounding Interferometer (IASI) onboard MetOp satellite, in addition to ERA-Interim data, to study their characteristics. The lower atmospheric data over the AS have been examined first to identify the areas where MIs are predominant and occur with higher strength. Based on this information, a detailed study has been made to investigate their characteristics separately in the eastern AS (EAS) and western AS (WAS) to examine their contrasting features. The initiation and dissipation times of MIs, their percentage occurrence, strength, etc., has been examined using the huge database. The relation with monsoon activity (rainfall) over Indian region during normal and poor monsoon years is also studied. WAS $\Delta T$ values are $\sim 2 \mathrm{~K}$ less than those over the EAS, $\Delta T$ being the temperature difference between 950 and $850 \mathrm{hPa}$. A much larger contrast between the WAS and EAS in $\Delta T$ is noticed in ERA-Interim data set vis-àvis those observed by satellites. The possibility of detecting MI from another parameter, refractivity $N$, obtained directly from another satellite constellation of GPS Radio Occultation (RO) (COSMIC), has also been examined. MI detected from IASI and Atmospheric Infrared Sounder (AIRS) onboard the NOAA satellite have been compared to see how far the two data sets can be combined to study the MI characteristics. We suggest MI could also be included as one of the semipermanent features of southwest monsoon along with the presently accepted six parameters.
\end{abstract}

\section{Introduction}

Monsoon inversion (MI) is one of the criteria providing a stability condition over the western Arabian Sea (AS), extending sometimes through to the west coast of India. MI controls the midtropospheric moisture content during the different phases of the monsoon. This shallow layer of low-level inversion (below $\sim 800 \mathrm{hPa}$ ) will act as a barrier in uplifting of the moisture, and could act like a wave guide for transport of water vapour to the mainland. The fluctuation of the rainfall over the west coast of India is more closely related to changes in monsoon circulation over the AS (Das, 2002). The AS is located at the north head of the Indian Ocean. During the monsoon season, Indian rainfall is also dependent on the physical processes occurring over the AS like sea surface temperature (SST), Somali low-level jet stream, the advection of hot air from the Arabian Desert, etc. These have a profound effect on strength of MI. Thus, MI has been known to be intimately associated with the activity of the Indian southwest monsoon and has a close link with active and break spells (Narayanan et al., 2004).

MIs were first detected in 1964 during International Indian Ocean Expedition (IIOE) from ship radiosonde data by Colon (1964) and Ramage (1966). Subsequently, from satellite-derived temperature and humidity data, this feature was detected by Narayanan and Rao (1981). They detected MI despite the coarse vertical resolution $(\sim 2 \mathrm{~km})$ of the TIROS-N satellite temperature sounding instruments (Schlatter, 1981) of the 1970s-1980s compared to the vertical extent (about $1-1.5 \mathrm{~km}$ ) of the phenomena itself. They used a simple differencing technique by finding the difference, $\Delta T$, of sea skin temperature and $1000-850 \mathrm{hPa}$ mean 
layer temperature (MLT) from the satellite sounding data. By adopting this differencing procedure, they assumed that most of the systematic errors and/or limitations of retrieval methods and vertical resolution of satellite soundings may be getting significantly minimized. Furthermore, the spatial and temporal nature of MIs is quite large compared to normal boundary layer inversions observed over land and other oceans.

Using data of about 150 ship radiosonde and aircraft dropsonde profiles and concurrent TIROS-N satellite sounder data of the MONsoon EXperiment (MONEX) conducted in 1979 , they showed that regions with $\Delta T \leq 2 \mathrm{~K}$ in satellitederived atmospheric temperatures are associated with the AS MI. Study of these MIs over the western AS was one of the three major objectives of MONEX/FGGE-1979 (WMO, 1976). These are seen to be much stronger (temperature departures from normal profiles in some cases being as high as $\sim 6 \mathrm{~K}$ in the lower $1-2 \mathrm{~km}$ height region) in contrast to the inversions observed over land or associated with trade wind inversions $(\sim 1-2 \mathrm{~K})$.

MIs are characterized by both a vertical temperature increase in the altitude region from $0.5 \mathrm{~km}$ (in some cases even from surface) to $\sim 2 \mathrm{~km}$ and with a sharp fall in relative humidity $(\mathrm{RH})$ above this altitude region. Some of the observed features of MIs reported from the limited observations to date (Colon, 1964; Ramage, 1966; Narayanan and Rao, 1981, 1989) are (i) strength decreases and base increases from the west to the east AS, (ii) oscillation of its lateral boundary from west to east with the activity of monsoon and (iii) associated oscillation of midtropospheric water vapour content from east to west, i.e. opposite to the boundary of temperature inversion. The two primary causes proposed (Colon, 1964) for formation and maintenance of monsoon inversion are (a) hot air advection from Arabia $(\sim 700 \mathrm{hPa})$ riding over cool maritime air (at levels below $\sim 800 \mathrm{hPa}$ ) from the south Indian Ocean and (b) subsidence over the western AS associated with monsoon convection over the Indian mainland. This large-scale subsidence had played a major role in the maintenance of MI during the prolonged weak monsoon of 2002 (Narayanan et al., 2004).

However, not much attention was paid to the study of MI due to paucity of freely available data over this region. The spatial density of TIROS-N satellite data available to the global research community in 1979 was just a single temperature-humidity profile a day in a latitude-longitude grid box of $2.5^{\circ} \times 2.5^{\circ}$ (Kidder and Haar, 1995). Narayanan and Rao (1981) had to temporally adopt a pentad and spatially adopt a $5^{\circ} \times 5^{\circ}$ average to detect statistically significant results from the meager data available then. Since 2008, the number of temperature and humidity profiles from polarorbiting satellites is nearly 2 orders of magnitude higher (about one vertical profile every $50 \times 50 \mathrm{~km}$, twice each day and from two satellites) along with much better vertical and spectral resolution. Thus, it has become possible now to study MI phenomena in greater detail. However, no in situ data after the 1979 experiment are available in this region.

In the present study, we have used the high-resolution and better-accuracy temperature and humidity profile data obtained from the Infrared Atmospheric Sounding Interferometer (IASI) onboard the MetOp satellite. These data have higher vertical resolution, i.e. $\sim 400 \mathrm{~m}$ below $700 \mathrm{hPa}$, which is much better than those of TIROS-N of the MONEX 1979 period. Further, ERA-Interim data have been used to compare the MI features seen in the data with those from the satellite data. In order to explain the relative contribution of subsidence and convection on MI, wind observations from ERA-Interim reanalysis data have been used. The temperature-humidity profile data are also available from the NOAA Atmospheric Infrared Sounder (AIRS) since 2002, all of which have also been analysed in the same way as the IASI data. However, we have not presented those results here, because of some inconsistencies (i.e. sometimes ERAInterim data show MI but AIRS has different features such as no presence of MI; profile-to-profile matches between AIRS and ERA-Interim data sets are not seen, i.e. inversion type changes or level of inversion changes) observed between the IASI and AIRS data in studying the MI features. Thus, we have confined the present study to data only from one instrument, viz., IASI, which had been reported as having better performance (Smith et al., 2015). This is expected to also ensure that the results of temporal and spatial gradients of $\Delta T$ presented here (featuring MI) will be mutually consistent, even if the absolute values of temperature-humidity may have some errors. We have, however, included one section comparing the results of these two instruments for studying the MI features. We have also shown, to a limited extent, the potential of the GPS RO measured refractivity profiles in delineating inversion regions. For this, we have also used the MONEX in situ temperature-humidity profiles of 1979.

\section{Data}

As mentioned earlier, data from a variety of instruments have been used in this study: the IASI satellite instrument, ERA-Interim reanalysis data and in situ dropsondes and radiosondes data obtained during MONEX 1979. Limited AIRS sounder data and GPS RO data have also been presented for comparison purposes. A short description of each of these data is given in Sect. 2.1-2.5 and is also summarized in Table 1.

\subsection{IASI observations}

IASI is a thermal infrared, nadir-looking Fourier transform spectrometer which measures the Earth's surface and the atmospheric radiation over a spectral range of $645-2760 \mathrm{~cm}^{-1}$ with a $0.5 \mathrm{~cm}^{-1}$ spectral resolution. The IASI field of view is a matrix of $2^{\circ} \times 2^{\circ}$ circular pixels, each with a diameter 
Table 1. Data details for accuracy and/or error and availability.

\begin{tabular}{|c|c|c|c|c|c|}
\hline & IASI & AIRS & COSMIC GPS-RO & ERA-Interim & $\begin{array}{l}\text { MONEX } 1979 \\
\text { in situ data }\end{array}$ \\
\hline $\begin{array}{l}\text { Launch of } \\
\text { satellite }\end{array}$ & $\begin{array}{l}\text { MetOp-A launched } \\
\text { in October 2006, } 8461 \\
\text { spectral channels }\end{array}$ & $\begin{array}{l}\text { Aqua launched in May } \\
2002,2378 \text { spectral } \\
\text { channels }\end{array}$ & $\begin{array}{l}\text { GPS-RO microsatellite } \\
\text { receiver launched in } \\
\text { April } 2006\end{array}$ & - & May-August 1979 \\
\hline $\begin{array}{l}\text { Data availabil- } \\
\text { ity from }\end{array}$ & August 2008 & 2003 & April 2006 & 1979 & May-August 1979 \\
\hline $\begin{array}{l}\text { Data used } \\
\text { in the present } \\
\text { study }\end{array}$ & $\begin{array}{l}\text { June-September } \\
\text { 2009-2013 }\end{array}$ & $\begin{array}{l}\text { June-September } \\
\text { 2009-2013 }\end{array}$ & $\begin{array}{l}\text { June-September } \\
\text { 2009-2013 }\end{array}$ & $\begin{array}{l}\text { June-September } \\
\text { 2009-2013 }\end{array}$ & May-August 1979 \\
\hline $\begin{array}{l}\text { Accuracy in } \\
\text { temperature }\end{array}$ & $\begin{array}{l}\sim 1 \mathrm{~K}(\mathrm{RMS}) \text { at a vertical } \\
\text { resolution of } 1 \mathrm{~km} \\
\text { (Clerbaux et al., } 2007 \text {, } \\
2009 \text { ) }\end{array}$ & $\begin{array}{l}\sim 1 \mathrm{~K} \text { at a vertical } \\
\text { resolution of } 1 \mathrm{~km} \\
\text { (Susskind et al., 2003) }\end{array}$ & $\begin{array}{l}\text { Generally } \sim 100 \mathrm{~m} \text { in } \\
\text { the lower troposphere } \\
(\text { not for } T \text { ) }\end{array}$ & $\begin{array}{l}0.5-1.0 \mathrm{~K} \text { at a vertical } \\
\text { resolution of } 0.8-1.0 \mathrm{~km}\end{array}$ & $\begin{array}{l} \pm 1^{\circ} \mathrm{C} \text { in } 4 \text { vertical } \\
\text { levels resolution } \\
\text { (WMO report) }\end{array}$ \\
\hline $\begin{array}{l}\text { Accuracy in } \\
\text { humidity }\end{array}$ & $\begin{array}{l}\sim 10-15 \% \text { accuracy with } \\
\text { a } 1-2 \mathrm{~km} \text { vertical reso- } \\
\text { lution (Clerbaux et al., } \\
2007,2009 ; \text { Schlüssel et } \\
\text { al., 2005) }\end{array}$ & $\begin{array}{l}\sim 15 \% \text { accuracy with a } \\
2 \mathrm{~km} \text { vertical layer re- } \\
\text { solution (Susskind et } \\
\text { al., 2003) }\end{array}$ & - & $\begin{array}{l}\sim 7.0-20 \% \text { at a vertical } \\
\text { resolution of } 0.8-1.0 \mathrm{~km}\end{array}$ & $\begin{array}{l} \pm 30 \% \text { at a vertical } \\
\text { resolution of } 4 \text { levels }\end{array}$ \\
\hline $\begin{array}{l}\text { Accuracy in } \\
\text { refractivity }\end{array}$ & - & - & $\begin{array}{l}400 \mathrm{~m}-1.4 \mathrm{~km} \\
\text { (Kursinski et al., 1997) }\end{array}$ & - & - \\
\hline $\begin{array}{l}\text { Horizontal } \\
\text { resolution }\end{array}$ & $15 \mathrm{~km}$ & $25 \mathrm{~km}$ & $\begin{array}{l}\text { globally } 2000 \\
\text { soundings per day }\end{array}$ & $1.5^{\circ} \times 1.5^{\circ}(\sim 80 \mathrm{~km})$ & $500 \mathrm{~km}$ \\
\hline Pressure levels & $\begin{array}{l}1100-0.0161 \mathrm{hPa}- \\
100 \text { levels }\end{array}$ & $\begin{array}{l}1100-0.0161 \mathrm{hPa}- \\
100 \text { levels }\end{array}$ & $\begin{array}{l}70 \% \text { of occultations } \\
\text { penetrate below } 1 \mathrm{~km} \\
\text { (Anthes et al., 2008) }\end{array}$ & $\begin{array}{l}1013-1 \mathrm{hPa} \\
37 \text { levels }\end{array}$ & $1000-294$ \\
\hline $\begin{array}{l}\text { Local equator } \\
\text { crossing time }\end{array}$ & $\begin{array}{l}\text { 09:30 LT } \\
\text { descending node }\end{array}$ & $\begin{array}{l}\text { 13:30 LT } \\
\text { ascending node }\end{array}$ & - & - & - \\
\hline Swath & $2200 \mathrm{~km}$ & $1650 \mathrm{~km}$ & - & - & - \\
\hline
\end{tabular}

footprint of $12 \mathrm{~km}$ at nadir. It measures an average at each location on the Earth's surface twice a day (at 09:30 and 21:30 local time), every $50 \mathrm{~km}$ at nadir, with an excellent horizontal coverage due to its polar orbit and its capability to scan across track over a swath width of $2200 \mathrm{~km}$. The IASI instrument (Clerbaux et al., 2007, 2009) measures temperature profiles in the troposphere and lower stratosphere with a high accuracy ( $\sim 1 \mathrm{~K}$ root mean square) at a vertical resolution of $1 \mathrm{~km}$ in the lower troposphere), as well as humidity profiles in the troposphere (10-15\% accuracy with a $1-2 \mathrm{~km}$ vertical resolution) primarily for numerical weather prediction (Schlüssel et al., 2005). More details about retrieval and validation are presented in Kwon et al. (2012). The support products, which we have used, are available at 100 pressure levels at $50 \times 50 \mathrm{~km}$ horizontal grid spacing, but we restrict the data from surface to $600 \mathrm{hPa}$ for our analysis.

\subsection{Dropsonde and radiosonde measurements MONEX (1979)}

For the in situ ground truth comparisons over the AS between the longitudes $55-75^{\circ} \mathrm{E}$ we also make use of the aircraft dropsondes and ship radiosonde observations obtained during MONEX 1979. MONEX was conducted during MayJuly 1979 and there were 416 radiosondes and 412 dropsondes measurements over the AS. It may be noted that after the MONEX campaign in 1979, no campaign has been organized to gather in situ data over the western or central AS. During the Indian ARMEX programme (2002), however, some in situ data were available but only in the far eastern AS (east of $70^{\circ}$ ) near the coast of India. Table 2 summarizes the comparison of in situ observations with satellite data of 1979 by Narayanan and Rao (1981). This information on $\Delta T$ criterion has been used as the reference in the present study. In this regard, it is worth to quote the recent study by Dwivedi et al. (2016) who has reported observations of temperature inversions during July-August over Muscat and Salah (east Saudi Arabian coast) from concurrent radiosonde and IASI data.

\subsection{ERA-Interim data}

The European Centre for Medium Range Weather Forecasts (ECMWF) ERA-Interim is one of most advanced in operational use for diagnosing the global atmosphere with an accuracy that is less than what is theoretically possible (Sim- 
Table 2. Comparison of aircraft profiles with satellite data.

\begin{tabular}{lccc}
\hline & Aircraft profiles & \multicolumn{2}{c}{ Near simultaneous satellite data } \\
\cline { 3 - 4 } & & $\Delta T \leq 2{ }^{\circ} \mathrm{C}$ & $\Delta T \geq 3{ }^{\circ} \mathrm{C}$ \\
\hline $\begin{array}{l}\text { No. of profiles with well-marked } \\
\text { inversion below 850 mbar }\end{array}$ & 30 & 23 & $\begin{array}{c}7 \\
\text { (for four of them } \Delta T=3{ }^{\circ} \mathrm{C} \text { ) }\end{array}$ \\
\hline $\begin{array}{l}\text { No. of profiles without } \\
\text { well-marked inversion }\end{array}$ & 129 & 0 & 129 \\
\hline
\end{tabular}

Regenerated from Narayanan and Rao (1981).

mons and Hollingsworth, 2002; Simmons et al., 2007). The selected variables are specific humidity along with the temperature on different pressure levels. The atmospheric data are available at $0.125^{\circ} \times 0.125^{\circ}$ latitude and longitude grids on 37 pressure levels from 1000 to $1 \mathrm{hPa}$; however, for the present study, we have used the data of 14 pressure levels from 1000 to $600 \mathrm{hPa}$ for the period of 2009 to 2013 . Vertical as well as horizontal strength of MI has been examined from these data sets and compared with satellite observations.

\subsection{AIRS observations}

AIRS onboard the Earth Observing System (EOS)-Aqua satellite of NASA was launched in 2002. This is also a polar orbiting satellite which crosses the equatorial latitudes at 13:30 and 01:30LT for the ascending and descending passes, respectively. The orbit period is $98.99 \mathrm{~min}$, and the orbit is sun synchronous with consecutive orbits separated by $2760 \mathrm{~km}$ at the equator. AIRS has a field of view of $1.1^{\circ}$ and provides a nominal spatial resolution of $13.5 \mathrm{~km}$ for IR channels and approximately $2.3 \mathrm{~km}$ for visible and near-IR channels. AIRS data together with data from the Advanced Microwave Sounder Unit (AMSU) (Lambrigtsen, 2003) are used. We make use of AIRS support data which have higher vertical resolution with 100 levels between 1100 and $0.016 \mathrm{hPa}$. In this study, we use the data from surface to $600 \mathrm{hPa}$ which have vertical resolution of $30-20 \mathrm{hPa}$. These data are available since 2003. We use data from 2009 to 2013 to compare with other data sets.

\subsection{COSMIC GPS RO}

GPS RO technique is also a remote-sounding satellite technique, and it uses the radio signals received onboard a low Earth-orbiting satellite from atmospheric limb sounding. The GPS RO measurements have a vertical resolution ranging from $400 \mathrm{~m}$ to $1.4 \mathrm{~km}$, which is much better than that of any other satellite data (Kursinski et al., 1997). COSMIC has a vertical resolution of $\sim 100 \mathrm{~m}$ in the lower troposphere for temperature. The COSMIC GPS RO was successfully launched in mid-April 2006 (Anthes et al., 2008). Since 17 July 2006, COSMIC GPS RO provides accurate and high vertical resolution profiles of atmospheric parameters that are almost uniformly distributed over the globe. COSMIC provides a direct estimate of refractivity (from measurement of bending angle by GPS technique) at very high vertical resolution, but has a poor frequency of revisits.

\section{Methodology and analysis procedure}

As mentioned earlier, MI was first observed by Colon (1964) and Ramage (1966) over the AS from ship radiosonde profiles. They reported that MI lies between 900 and $800 \mathrm{hPa}$ with strong intensity over the western AS (WAS) and weakens as its base rises and moves to the eastern AS (EAS). Following this study, Narayanan and Rao (1981) have shown the MI presence using the temperature difference $(\Delta T)$ between the TIROS-N derived sea skin temperature and atmospheric layer mean temperature (between 1000 and $850 \mathrm{hPa}$ ).

Note that the lapse rate $(\mathrm{d} T / \mathrm{d} z)$ of atmosphere at the tropospheric altitudes is a negative quantity. However, in this study (and also in Narayanan and Rao, 1981), we have considered $\Delta T$ as the temperature difference between a lower level (higher temperature) and a higher level (lower temperature), so is a positive quantity between $\sim+6$ and $+7 \mathrm{~K}$. For inversion regions, it is negative or a small positive quantity (i.e. less than $+2 \mathrm{~K}$ ).

After considering several limitations in the satellite data of that time, Narayanan and Rao (1981) finally considered MI when the difference $\Delta T$, between surface and layer mean temperature (of 1000 to $850 \mathrm{hPa}$ ), is $2 \mathrm{~K}$ or less, which otherwise was greater than $3 \mathrm{~K}$. Since then, several improvements in the satellite instruments, retrieval techniques and data products have come up in these 3 decades.

Extensive AS MI features were observed from in situ measurements during FGGE-MONEX 1979. Figure 1a shows a typical example of MI observed in $T$ and $\mathrm{RH}$ data obtained on 27 June 1979 at 06:56 GMT at $20^{\circ} \mathrm{N}, 62^{\circ} \mathrm{E}$ from radiosonde. In this example, MI is starting from the surface and temperature departure is as high as $\sim 10 \mathrm{~K}$ from a normal lapse rate profile at $900 \mathrm{hPa}$. The vertical extent of inversion varies from $0.5 \mathrm{~km}$ to even more than $1 \mathrm{~km}$. It is to be noted that AS MIs are much stronger and long lasting, i.e. they have less diurnal variation than normal boundary lay- 


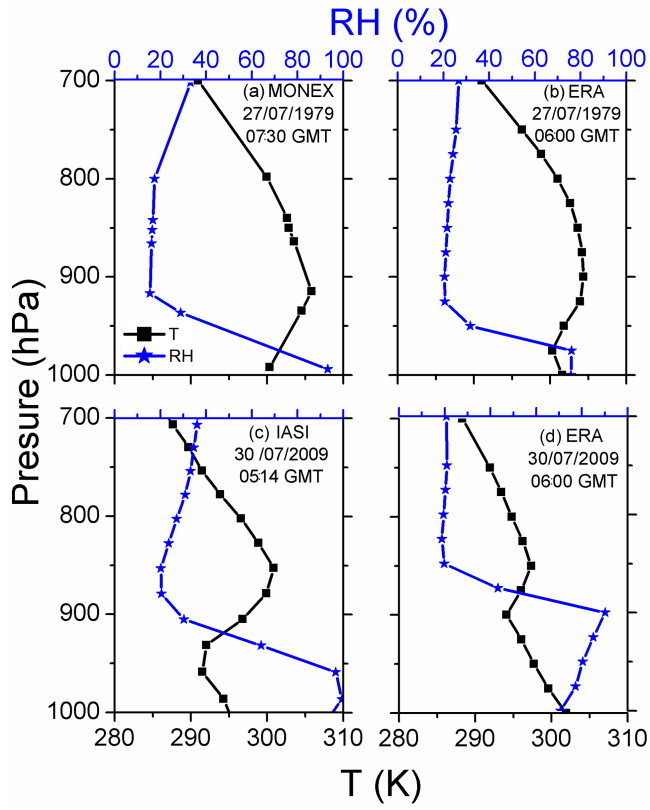

Figure 1. Typical examples showing MI in $T$ and RH on (a) 27 June 1979 at $07: 30 \mathrm{GMT}$ at $20^{\circ} \mathrm{N}, 60^{\circ} \mathrm{E}$ measured by radiosonde during MONEX experiment, (b) same as panel (a) but at 06:00 GMT from ERA-Interim (ERA), (c) 30 July 2009 at 05:14 GMT at $22^{\circ} \mathrm{N}, 68^{\circ} \mathrm{E}$ by IASI, (d) 30 July 2009 by ERA-Interim at same location but at 06:00 GMT. Note that scale for RH is shown in the top axis of panels (a) and (b).

ers and persist for many days compared to those over land regions.

A detailed analysis is made in this study by considering several thousands of profiles obtained from different satellite observations now available over the AS for in-depth study of MI. Since the MIs occur at low levels, first we tried with the earlier adopted criteria of Narayanan and Rao (1981) i.e. by taking the difference between sea surface (skin) temperature and $925 \mathrm{hPa}$ level (mean pressure level of $1000-850 \mathrm{hPa}$ MLT of TIROS-N data of the 1980 timeframe) temperature and found those to be noisy for detecting MI. To avoid the surface emissivity effects in the retrieval at or near surface (from the sounder instrument), we adopted the lower level in the present study as $950 \mathrm{hPa}$ instead of sea surface/skin temperature. It was considered not appropriate to use sea surface/skin temperature (though it may be of higher accuracy) from a different source (like an imager onboard the same satellite) for estimating $\Delta T$. It was felt that this will not give the advantage of the differencing procedure employed earlier to detect inversion (Narayanan and Rao, 1981). This level criterion (950-850 hPa) was arrived at after a detailed examination of $\Delta T$ at a few more level intervals (viz. 1000-900, $1000-850 \mathrm{hPa}$, etc.).

Thus, we have used

$\Delta T=T(950 \mathrm{hPa})-T(850 \mathrm{hPa})$ to delineate MI. However, the actual levels used were 958 and $852 \mathrm{hPa}$ at which the support data are available from the NOAA website.

While considering the normal atmospheric lapse rate of +6 to $+7 \mathrm{~K} \mathrm{~km}^{-1}$ (average of 340 noninversion cases obtained during MONEX, figure not shown), it is expected to observe a $\Delta T$ of +6 to $+7 \mathrm{~K}$ between 950 and $850 \mathrm{hPa}(\sim 1 \mathrm{~km}$ height difference). Note that Narayanan and Rao (1981) have identified the inversion (noninversion) region as $\Delta T \leq+2 \mathrm{~K}(\Delta T>+2 \mathrm{~K})$ in TIROS-N satellite data for a height range difference of $\sim 0.75 \mathrm{~km}$. For the present study (for $1 \mathrm{~km}$ height difference) the same would translate to $\Delta T \sim+2.7 \mathrm{~K}$ for inversion delineation. However, to provide margin of error, we have still considered $\Delta T \leq+2 \mathrm{~K}$ as criterion of the inversion region. The interval 2.0 to $2.7 \mathrm{~K}$ may still be a grey region which could be interpreted as the inversion region on some occasions. The criterion of $\Delta T \geq+4 \mathrm{~K}$ as the noninversion regions has been adopted. In the example shown in Fig. 1a, $\Delta T$ is (minus) $-1.3 \mathrm{~K}$ (note however, that the actual inversion value is $\sim-5 \mathrm{~K}$ between surface and $900 \mathrm{hPa}$ ).

In general, a sudden drop in the water vapour just above the inversion is observed (e.g. RH drop of $\sim 70 \%$, as shown in Fig. 1a). Since all the data sources mentioned in Sect. 2 provide water vapour information, we also have examined the changes happening in water vapour near or above the inversion altitude. In general, inversion is identified in the temperature (water vapour) where it increases (decreases sharply) instead of decreasing (decreasing gradually) with altitude. For obtaining detailed characteristics of MIs over the AS, we have selected three $3^{\circ} \times 3^{\circ}$ grid boxes centred at latitude $18.5^{\circ} \mathrm{N}$, and located at longitudes $60^{\circ} \mathrm{E}$ as the WAS, $64^{\circ} \mathrm{E}$ as the CAS (central AS), $71^{\circ} \mathrm{E}$ as the EAS (as shown in Fig. 3).

\section{Quality checks for the profiles and volume of data}

Each temperature profile from the satellite data was interpolated from surface to $500 \mathrm{hPa}$ (26 levels of support data) at $0.25 \mathrm{~km}$ intervals for our preliminary analysis. We have used the quality flags 0 and 1 from the given data set which are corresponding to best and good. There were many erroneous profiles which could be observed even from a cursory examination of the data. Such poor profiles are discarded. The temperatures at a few levels were far off the normal profiles. To account for these types of profiles, we applied a quality check to filter out spurious data. All profiles of July and August of 2009 (poor monsoon year) and 2011 (normal monsoon year) were sorted out in $3^{\circ} \times 3^{\circ}$ boxes of the WAS and EAS. For each month the mean and standard deviation were obtained for each interpolated level separately. Those profiles for which the data at any one level was lying beyond \pm 2 sigma of the mean, were not considered for further analysis. From this procedure we saw that nearly $25-30 \%$ of profiles were filtered out. 
Using these quality-checked profiles, the procedure for selecting the right levels for calculating $\Delta T$ was established. Thereafter, for all the other monsoon days of the 5 years, we have computed $\Delta T$ for individual profiles by an automated procedure (without resorting to examining each profile). They were grouped and their $\Delta T$ values averaged in $1^{\circ} \times 1^{\circ}$ bins over the whole AS region. Diurnal variation of $\Delta T$ was examined for a few months of data. Once we made sure that this is not discernible, the day and night data of a calendar day were merged in $1^{\circ} \times 1^{\circ}$ boxes.

For further analysis, the average $\Delta T$ values for the day ( $24 \mathrm{~h}$ period) at $1^{\circ} \times 1^{\circ}$ grids have been used. Due to averaging of $\Delta T$ of all the profiles in $1^{\circ} \times 1^{\circ}$ boxes and morning and evening overpasses ( $\sim 6$ to 8 values of $\Delta T$ in $24 \mathrm{~h}$ ), the strength of MI may be getting somewhat reduced (as MI occurs at slightly different levels within a vertical range of $25-50 \mathrm{hPa}$, for different profiles in the same $1^{\circ} \times 1^{\circ}$ box). For some studies (e.g. for Figs. 2, 4, 5, etc.), we have used only a section of these data sets. The total number of profiles considered for the 5 years amount to nearly half a million, each for AIRS and IASI, considering that nearly $30 \%$ profiles did not pass our quality check.

\section{Results and discussions}

\subsection{Monsoon inversions observed in satellite and ERA-Interim data sets}

Figure 1a and b show MI observed on 27 June 1979 at 07:30 GMT at $20^{\circ} \mathrm{N}, 60^{\circ} \mathrm{E}$ through MONEX radiosonde and ERA-Interim data, respectively. The detailed comparison study between TIROS-N satellite data of 1979 and concurrent in situ MONEX radiosonde profiles for the 1979 southwest monsoon carried out by Narayanan and Rao (1981) is summarized in Table 2. This was the only occasion (1979) when in situ data were available over the AS to compare with satellite soundings. Thus, comparison of current satellite observations is being done in this study with ERA-Interim data. In this case, ERA-Interim data also catches the inversion but with a lesser rise in temperature $(\sim 3-4 \mathrm{~K})$ and decrease in RH $(\sim 60 \%)$. To show the efficiency and strength of currently available satellite measurements to delineate features of MI over the AS, typical profiles of temperature and RH obtained from collocated IASI and ERA-Interim on 30 July 2009, 05:30 GMT are plotted in Fig. 1c and d, respectively. A clear MI in the satellite profile and ERA-Interim can be noticed, though with somewhat varying strengths and base of inversion height. However, the top height of the inversion is consistent. These are the first reported results of MI features seen directly from the satellite observations over the AS which were shown earlier by Narayanan and Rao (1981) in an indirect way by using $\Delta T$ indices. In general, in the individual satellite profiles, we are able to see the MI strengths ranging from $\sim+2$ to $-6 \mathrm{~K}(-8.8 \mathrm{~K}$ being the actual temper-

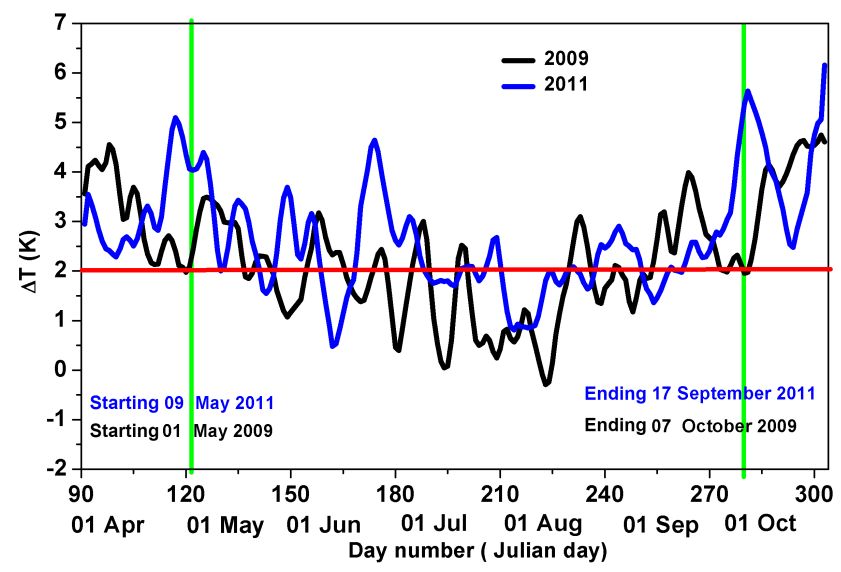

Figure 2. Time series of $\Delta T$ for beginning and end of MI from April to October 2009 (black) and 2011 (blue). Green vertical lines show beginning (1 May 2009) and end (7 October 2009) time for MI.

ature difference between 930 and $850 \mathrm{hPa}$ in Fig. 1c). These MI lie mostly below $850 \mathrm{hPa}$ level, but in rare occasions we could see them even up to $700 \mathrm{hPa}$ over the EAS, though of much weaker strength. The strength of MI is also seen to be decreasing from the WAS to EAS which will be discussed in detail in later sections.

Thus, in Fig. 1, we have seen examples of MI comparison between radiosonde and ERA-Interim (1979) and between IASI and ERA-Interim (2009). There are some minor inconsistencies by way of inversion heights in individual profiles of the three data sets. However, our objective here is to examine the large-scale characteristics of MI by considering average $\Delta T$ computed from individual profiles in $1^{\circ} \times 1^{\circ}$ grids.

\subsection{Contrasting behaviour of MI between the WAS and EAS}

As observed from Fig. 1, MI can lie between surface and $\sim 2 \mathrm{~km}$ during Indian summer monsoon (ISM) season (JJAS). Careful examination of time evolution of $\Delta T$ over the western AS reveals that MI appears around first half of May and dissipate around late September. Figure 2 shows the evolution of MI during 2 contrasting years (2009, a poor monsoon year, and 2011, a normal monsoon year). During the peak monsoon season of July-August, the difference in $\Delta T$ between the 2 years is significant. Also, MI is more frequently observed with higher strength during the peak monsoon months of July and August. To further investigate their contrasting features in the WAS and EAS, data only of July and August from 2009 to 2013 are presented.

In Fig. 3 we have summarized the three important characteristics of MIs: their base altitude, strength (as revealed by $\Delta T)$ and percentage occurrence during the complete season. For brevity, the results of only July and August, averaged for all 5 years (2009-2013) are shown in the figures. Figure 3a 

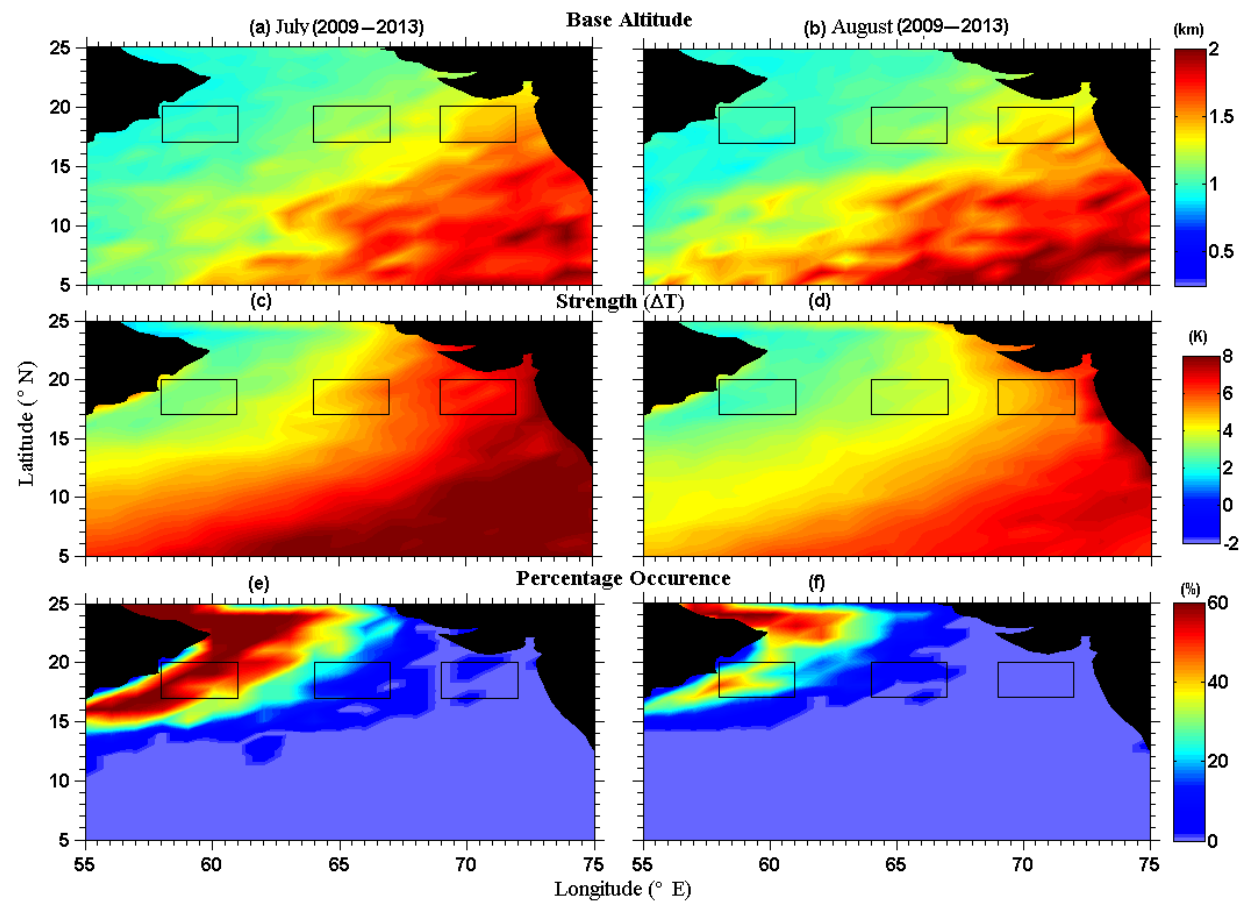

Figure 3. Base altitude occurrence of MI during (a) July, (b) August; $\Delta T$ (strength) of MI (c) July, (d) August; and percentage occurrence of MI days (e) July, (f) August, averaged during 2009-2013 observed by IASI (we select the WAS, CAS and EAS from this figure).

and $b$ show the spatial variation of base altitude of MI during July and August, respectively. The contrasting feature of base altitude of occurrence of MI is found mainly north of $15^{\circ} \mathrm{N}$ from the selected three grid boxes. It increases from the WAS (below $1 \mathrm{~km}$ ) to the EAS (above $1.5 \mathrm{~km}$ ) through CAS $(1.0-1.5 \mathrm{~km})$.

As mentioned earlier, from very limited observations, previous studies (Colon, 1964; Ramage, 1966; Narayanan et al., 2004) had suggested that strength and frequency of occurrence of the MI days will be more over the WAS than over the EAS. To investigate this contrasting behaviour of MI in detail from satellite soundings, we examined the spatial variations of $\Delta T$. Figure 3c (July) and d (August) show the strength of MI increasing from the EAS to the WAS and is prevalent mainly north of $15^{\circ} \mathrm{N}$ latitude extending from 15 to $25^{\circ} \mathrm{N}$ latitude and 55 to $68^{\circ} \mathrm{E}$ longitude. The strength of MI can be noticed as $\sim+2 \mathrm{~K}$ near the Arabian coast, but the normal environmental lapse rate condition of +6 to $+7 \mathrm{~K} \mathrm{~km}^{-1}$ is restored towards the Indian coast. From these figures, a clear contrast in $\Delta T$ with a difference of around $2 \mathrm{~K}$ in the southeast quadrant of the AS between July and August is also noticed. In general, the AS is covered with a lapse rate of $+4 \mathrm{~K} \mathrm{~km}^{-1}$, which is the condition for taking the atmosphere towards stability during the month of August. The Somali low-level jet stream is the location of permanent region of MI during the month of July. The spatial distribution of monsoon low-level jet stream (Roja Raman et al., 2011) reveals that the centre of the core is seen around $13^{\circ} \mathrm{N}$ and $60^{\circ} \mathrm{E}$ and strong shear exists between 850 and $700 \mathrm{hPa}$. Strong surface winds of the southwest monsoon produce an Ekman transport perpendicular to the wind flow with strong upwelling in the region which in turn brings the cool water from the deeper layers to surface. Simon et al. (2007) showed that the WAS region is the region of Somali upwelling, and also since the low-level jet stream and surface wind are of the order of $\sim 20 \mathrm{~m} \mathrm{~s}^{-1}$, they produce sufficient cooling and the air above this region is still warmer when compared to the upwelling area, producing strong inversion.

Figure $3 \mathrm{e}$ and $\mathrm{f}$ show the spatial variation of percentage occurrence (PO) of MI during July and August. PO is calculated corresponding to $\Delta T \leq+2 \mathrm{~K}$ criteria. In general, it is observed that the WAS shows a greater number of MI cases (50-70\%) compared to the EAS (10-20\%). ERA-Interim data show only $30-50 \%$ cases of MI over the WAS which will be described in detail in the following subsections. The maximum PO during the 4 months of monsoon over the WAS are $40 \%$ (June), $60 \%$ (July), $50 \%$ (August) and $30 \%$ (September) (figure not shown). The areal extent of the maximum PO is seen during July. During September, a very small area of the northern AS is covered with $\sim 50 \%$. No inversion is seen in the EAS box during the June and September periods. Despite its low strength $(\Delta T)$ PO shows maximum occurrence of $60 \%$ in July. Since the PO and strength of MI over the CAS are in between the features of the EAS and WAS, further discussions pertain only to the WAS and EAS boxes. 


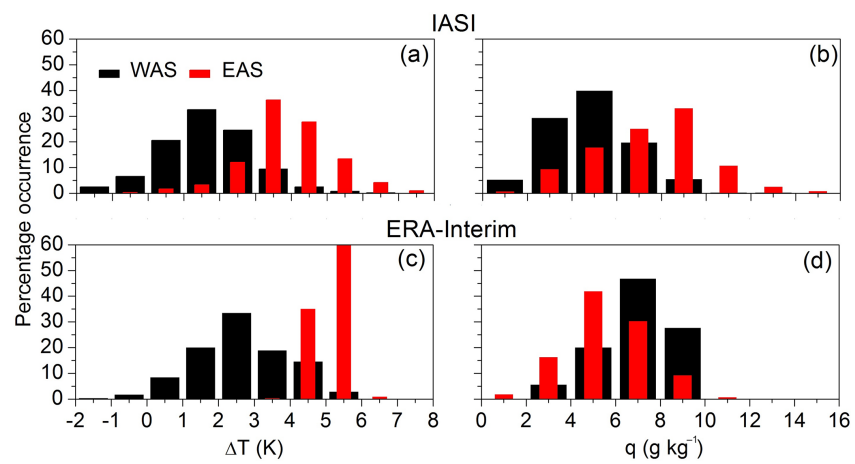

Figure 4. Percentage occurrence of (a) $\Delta T$ and (b) $q$ at $700 \mathrm{hPa}$ observed in the WAS and EAS during monsoon season of the years 2009-2013 for various ranges of $\Delta T$ and $q$ at $700 \mathrm{hPa}$ by IASI. Panels (c) and (d) are the same as panels (a) and (b) but obtained from ERA-Interim data.

The PO of $\Delta T$ values in different ranges observed in IASI for the five monsoon seasons is shown in Fig. 4. $\Delta T$ values range from -2 to $+6 \mathrm{~K}(0$ to $+7 \mathrm{~K})$ in the WAS (EAS) with the peak occurring around +1 to $+2 \mathrm{~K}(+3$ to $+4 \mathrm{~K})$. There are only a few values of $\Delta T$ less than $+2 \mathrm{~K}$ in the EAS. Similar analysis is also made using ERA-Interim data and is shown in bottom panels of Fig. 4. ERA-Interim data show the contrast between the WAS and EAS more clearly. In case of $q$ at $700 \mathrm{hPa}$ a difference of about $2 \mathrm{~g} \mathrm{~kg}^{-1}$ can be noticed, with the EAS having higher humidity values than the WAS in IASI. However, this feature is not observed in the ERA-Interim data.

To further examine the contrasting behaviour between the EAS and WAS, time series of $\Delta T$ and water vapour at $700 \mathrm{hPa}$ is considered for different years. Daily mean variations of $\Delta T$ and specific humidity, $q$, at $700 \mathrm{hPa}$ in the WAS and EAS during the monsoon season of the year $2012 \mathrm{ob}-$ served by IASI is shown in Fig. 5. Note that we have included results of all the days irrespective of whether MI is present or not. Three-point average smoothed curves are shown in the respective panels. In general, it can be seen that WAS $\Delta T(q$ at $700 \mathrm{hPa})$ values are $\sim+2 \mathrm{~K}\left(1-2 \mathrm{~g} \mathrm{~kg}^{-1}\right)$ less than those over the EAS for the season as a whole (Fig. 5a and b). During all the years (2009-2013) of the present study, IASI reveals (figure not shown) this feature. Similar analysis has been carried out using ERA-Interim reanalysis data and is shown in Fig. $5 \mathrm{c}$ and d. A clear contrast between the WAS and EAS in $\Delta T$ can be noticed in ERA-Interim data. A mean difference of $\sim 2 \mathrm{~K}\left(\sim 1 \mathrm{~g} \mathrm{~kg}^{-1}\right)$ can be noticed in $\Delta T$ ( $q$ at $700 \mathrm{hPa}$ ) between the WAS and EAS, with EAS values being lower. A cyclic behaviour in $\Delta T$ variations with a period of $\sim 20-25$ days in case of ERA-Interim is noticed but not observed in the satellite measurements. There exists no significant diurnal variation in $\Delta T$ (figure not shown). This was verified before averaging $\Delta T$ of all profiles (day and night) in the $1^{\circ} \times 1^{\circ}$ grids. Due to inversion and stability, moisture

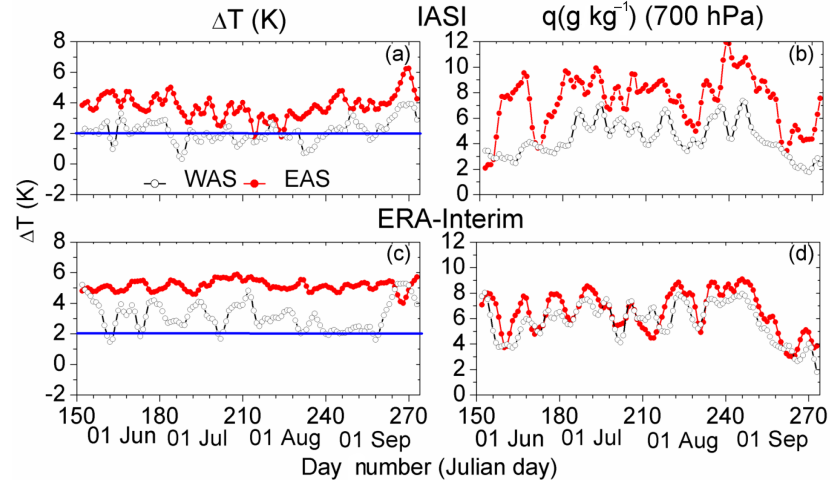

Figure 5. Time series of (a) $\Delta T$ and (b) $q$ at $700 \mathrm{hPa}$ observed over WAS and EAS grid boxes during the monsoon season of the year 2012 by IASI. Panels (c) and (d) are the same as panels (a) and (b) but obtained using ERA-Interim data. Three-point smoothed curves are shown.

is getting trapped at lower levels over the WAS compared to the EAS as indicated in Fig. 5b and d observed from IASI and ERA-Interim, respectively.

\subsection{Relation between MI over the AS and monsoon activity}

Past investigations (e.g. Gadgil and Joseph, 2003) showed that the monsoon features vary with activity of the monsoon. In general, during the active phase of the ISM, there will be more precipitation over central India $\left(18-28^{\circ} \mathrm{N}\right.$ and $65-$ $88^{\circ} \mathrm{E}$ ). Similar variations in precipitation during the monsoon season can also be expected on regional scales. Gadgil and Joseph (2003), Kripalani et al. (2004), Rajeevan et al. (2006) have considered the daily rainfall time series over central India during monsoon months along with the climate normal to delineate active and break periods over the Indian region. On the basis of this data, Rajeevan and Bhate (2009) have defined active and break phases over central India by considering the days exceeding the climate mean with +1 $(-1)$ standardised anomaly as active (break) periods, provided it should persist at least for 3 days (triad).

Figure 6 shows the latitude-longitude cross section of $\Delta T$ and $q$ at $700 \mathrm{hPa}$ for active (14-17 July 2009) and break (30 July-11 August 2009) spells for the monsoon season of 2009 observed using IASI and ERA-Interim data. Irrespective of the data source, $\Delta T$ and associated $q$ at $700 \mathrm{hPa}$ reveal that a large part of the WAS is covered with $\mathrm{MI}(\Delta T \leq+2 \mathrm{~K}$ and less moisture values) up to west of $\sim 68^{\circ} \mathrm{E}$ during the break spell as seen in Fig. 6a and e. In the north AS, MIs reach as close as the Gujarat coast during break spells (especially in ERA-Interim data), but are restricted to the WAS during active spells. During the active spell, the inversion regions from $\Delta T$ maps are discontinuous west of $65^{\circ} \mathrm{E}$ in Fig. 6c. Also strengths of $\Delta T$ in the WAS are more as observed by ERA-Interim than by IASI during break spells 


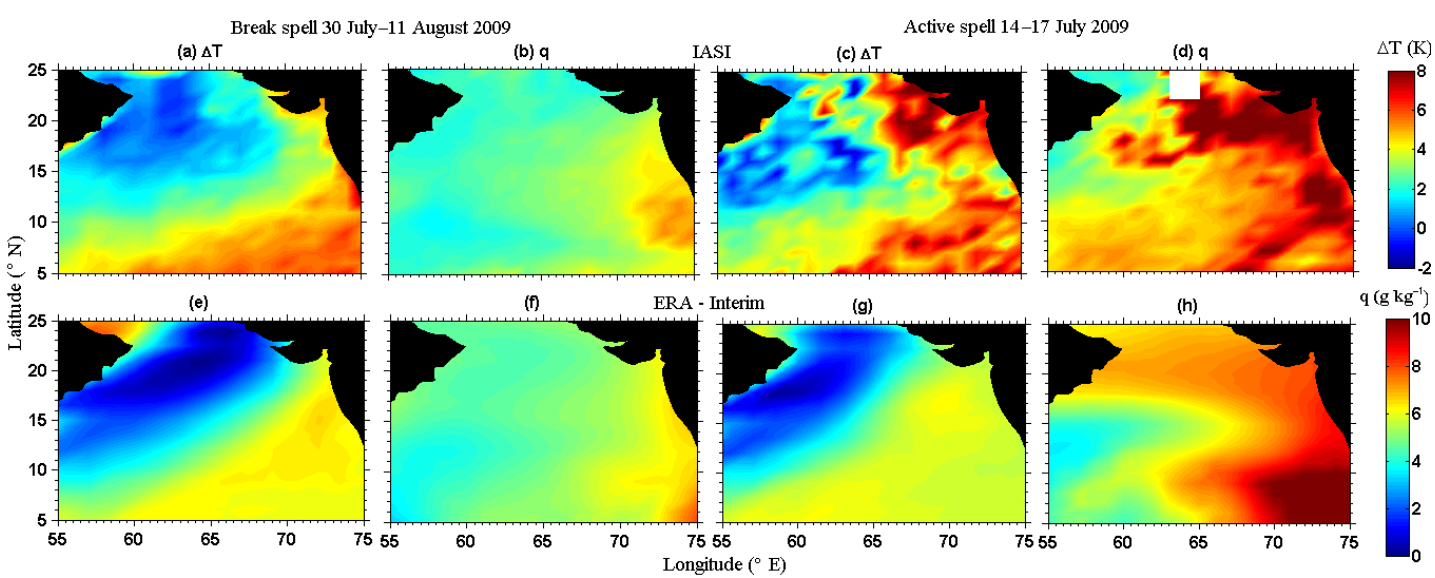

Figure 6. MI observed in (a) $\Delta T$ and (b) $q$ at $700 \mathrm{hPa}$ during break spells (30 July-11 August 2009) of the year 2009 by IASI. Panels (c) and (d) are the same as panels (a) and (b) but observed during active spells (14-17 July 2009). Panels (e-h) are the same as panels (a-d) but observed by ERA-Interim, respectively.

(30 July-11 August 2009). ERA-Interim data show (Fig. 6e and g) more smoothed results and there is less change in areal extent in this case. Specific humidity $q$ at $700 \mathrm{hPa}$ shows a clear result that AS has less moisture during the break spell and has more moisture during the active spell. One can notice the feature of inversion from the figure where water vapour is being trapped in the lower portion resulting in less moisture over the WAS and more over the EAS. Thus, the $q$ values also give a good indication of the inversion feature.

\subsection{MI during normal and poor monsoon years}

It is well known that strong MI suppresses the vertical development of clouds; rain cannot occur in such situations (Sathiyamoorthy et al., 2013). Using ARMEX (2002) data, Bhat (2006) could notice strong and persistent inversions in the atmosphere over the AS and west coast of India. The data proved very valuable as July 2002 rainfall was the lowest in the recorded history; the data collected over the AS and, on the west coast, helped in understanding the conditions that prevailed over the eastern AS during one of the worst monsoon years. The relation between MI and central India rainfall is further investigated by separating MI observed during normal (2010-2013) and poor (2009) monsoon years. Time variations of $\Delta T$ observed over the WAS during 2 contrasting years of 2009 and 2011 obtained from IASI measurements and ERA-Interim data are shown in Fig. 7. It can be seen that the good monsoon year 2011 has higher $\Delta T$ than the poor monsoon year 2009 (Fig. 7a), and is the same for $q$, i.e. higher value for the year 2011 (Fig. 7b). $\Delta T$ is observed to be lower by about $2 \mathrm{~K}$ during the season as a whole in the poor monsoon year when compared to the good monsoon year, suggesting the possibility of a variation of this parameter between normal and poor monsoon years. This aspect is clear from the right panels where difference between 2011 and 2009 observed in $\Delta T$ (Fig. 7c) and $q$ at $700 \mathrm{hPa}$
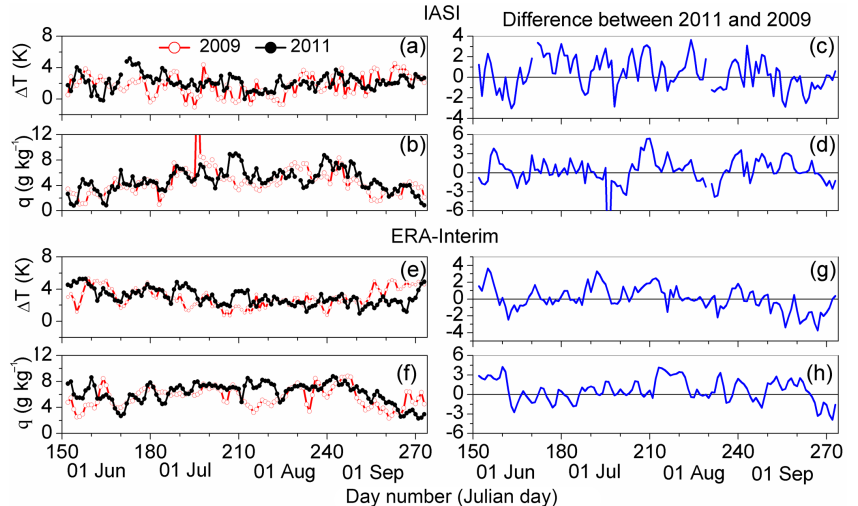

Figure 7. Time variations of (a) $\Delta T$ and (b) $q$ at $700 \mathrm{hPa}$ observed over the WAS during 2 contrasting years of 2009 and 2011 by using IASI measurements and ERA-Interim products $(\mathbf{e}, \mathbf{f})$. Difference between 2011 and 2009 observed in panel (c) $\Delta T$ and panel (d) $q$ at $700 \mathrm{hPa}$ for IASI and ERA-Interim products $(\mathbf{g}, \mathbf{h})$.

(Fig. 7d) are shown. From this figure we can infer that the year 2009 has less value of $\Delta T$ and less value for $q$ suggesting stronger MI during poor monsoon year. Note that during most of the time, the temperature in 2011 is higher (the difference between 2011 and 2009 showing positive values) and less temperature lapse rate means more stable layered atmosphere. In 2011, WAS temperatures show higher values revealing less MI over the AS when compared to 2009. The decreasing trend in $\Delta T$ is discernible in difference plots for some particular epochs. In general, ERA-Interim also show these features (Fig. 7e and f), but only to a moderate extent. It may be noted that these inferences are based on the results of only 1 poor monsoon year (2009). 


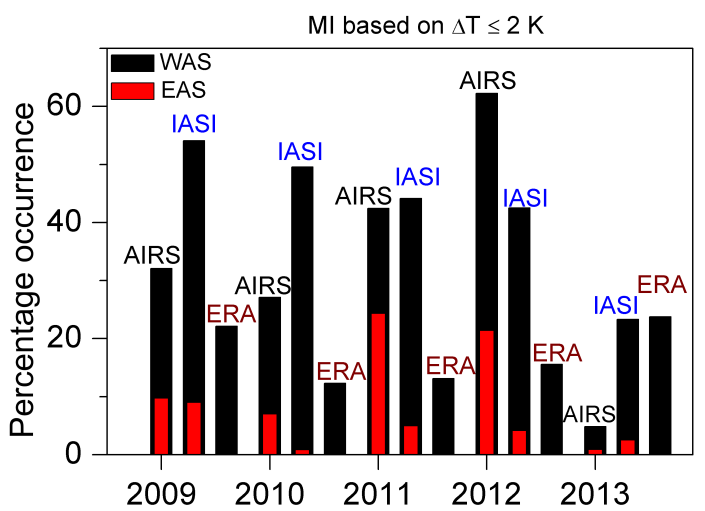

Figure 8. Percentage occurrence of MI observed with $\Delta T \leq 2 \mathrm{~K}$ using IASI, AIRS and ERA-Interim data during monsoon seasons of 2009-2013 over the WAS and EAS.

\subsection{Intercomparison of MI features with IASI, AIRS and ERA}

Intercomparison of the gross features of PO of MI (with $\Delta T \leq 2 \mathrm{~K}$ ) in the WAS and EAS estimated for the 5 years of monsoon season by IASI, AIRS and ERA-Interim data are shown in Fig. 8. In general, when we consider $\Delta T$ as a parameter to detect MI, clear contrasting features between the WAS and EAS with higher PO in the WAS can be noticed in all the data sources mentioned above. PO in the IASI measurements ranges from 23 to $54 \%$. Among these data sets, ERA-Interim shows huge differences in the percentage occurrences between the WAS and EAS, to the extent that not even a single MI is seen in the EAS in any year. Since the vertical resolution of the IASI temperature profiles is better than AIRS, higher PO of MI in the WAS is noticed throughout when compared to AIRS, except in the case of 2012. However, ERA-Interim being a combination of model and observations, it is not able to pick up MI in the EAS where the strength of inversion is also weak. The model appears to be smoothening the MI features of IASI when it is assimilated in the ERA-Interim.

Among the satellite observations, IASI shows higher PO of MI days than AIRS, except during 2012 over the WAS. A distinct contrast between the WAS and EAS with higher PO in the former region can be noticed. When we consider the EAS as a place to detect MI, AIRS always observed higher PO than IASI and almost nothing is noticed in ERA-Interim. Thus, we may infer that IASI is performing better than AIRS for detecting MI (as ERA-Interim is in better agreement with IASI rather than with AIRS). Note that large interannual variability in MI is observed and this is expected to reflect in the monsoonal activity over the Indian region. It can also be seen that there is a steady decrease of PO of MI as observed by IASI from 2009 to 2013. No such feature is observed in AIRS, which shows more random behaviour over the different years.
We have also analysed and compared the $\Delta T$ observed by IASI and AIRS over the WAS and EAS (figure not shown). The analysis suggests that these two data sets cannot be merged to study the small changes of $\Delta T$ in their intraseasonal and interannual variations. This and the other differences related to $q$ at $700 \mathrm{hPa}$ constrained us not to combine the AIRS data with IASI data in the present study.

\subsection{Monsoon inversion derived from other parameters}

Narayanan and Rao (1989) had also considered equivalent potential temperature $(\theta e)$ differences to study MI. $\theta e$ incorporates the effect of both temperature and humidity. However, the dynamic range of $\Delta \theta e$ is no better than that of $\Delta T$. Recall that the troposphere is statically stable on average, with a potential temperature gradient of $3.3 \mathrm{~K} \mathrm{~km}^{-1}$ (Wallace and Hobbs, 2006). We make use of another index here, i.e. atmospheric refractivity $(N)$ for identifying MI. Similar to $\theta e, N$ is another atmospheric parameter which is a function of temperature and water vapour. It was shown that better information on the boundary layer can be obtained from refractivity profiles than from virtual potential temperature, though both have temperature and water vapour information (Basha and Ratnam, 2009). $N$ has a higher dynamic range and vertical variation as compared to temperature $(\sim 15 N$ units vis-à-vis $2 \mathrm{~K}$ ). More advantage of using $N$ for delineating MI will be available, provided it is measured directly, for example, using GPS RO technique, instead of computing it from temperature and water vapour obtained from the sounders or from radiosonde. However, the spatiotemporal density of direct $N$ observations is too sparse to get meaningful statistics over equatorial regions.

We have computed $N$ from temperature and water vapour data of IASI (and MONEX radiosonde data), given by the expression

$N=77.6\left(\frac{P}{T}\right)+3.73 \times 10^{5}\left(\frac{e}{T^{2}}\right)$,

where $P$ is pressure, $T$ temperature and $e$ water vapour pressure.

Similar to $\Delta T$ we have defined an index " $\Delta N$ " as

$\Delta N=N(950 \mathrm{hPa})-N(850 \mathrm{hPa})$.

The profile of $N$ computed from the temperature and humidity profiles of dropsonde (Fig. 9a) of MONEX time is shown in Fig. 9b. A drastic decrease in $N$ (by $129 N$ units between 950 and $850 \mathrm{hPa}$ ) can be noticed near MI altitudes in this example. Thus, $N$ can also be taken as a potential parameter to delineate inversion and for studying spatial and temporal variations of MI.

In order to see the relation between $\Delta T$ and $\Delta N$, we have estimated $\Delta N$ using all the MONEX profiles obtained over the AS. These include both inversion and noninversion cases. There were 32 (346) profiles with inversion (noninversion). 


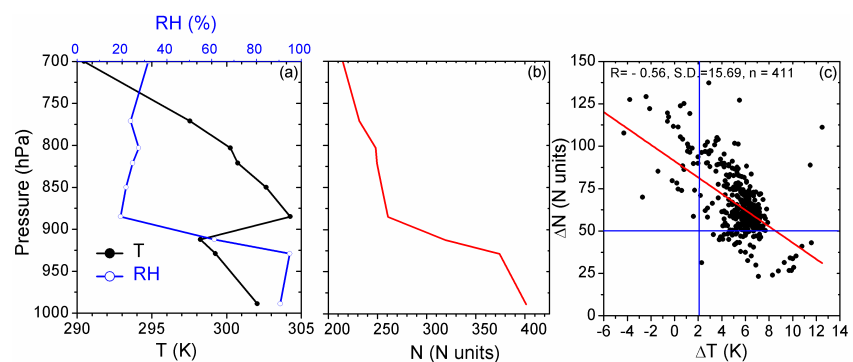

Figure 9. Typical examples showing $\mathrm{MI}$ in temperature and $\mathrm{RH}$ on (a) 27 June 1979 at 06:56 GMT at $20^{\circ} \mathrm{N}, 62^{\circ} \mathrm{E}$ obtained from dropsondes from MONEX experiment, (b) $N$ profile, (c) scatter plot of $\Delta T$ and $\Delta N$.

Note that $\Delta T \leq+2 \mathrm{~K}$ and $\Delta T>+4 \mathrm{~K}$ are only considered for obtaining above statistics and 34 profiles exist in the transition zone $(+2$ to $+3 \mathrm{~K})$. The scatter plot between $\Delta T$ and $\Delta N$ for all 411 in situ profiles of MONEX over the AS is shown in Fig. 9c. Correlation coefficients between the two parameters are found to be 0.56 with 15.7 as standard deviation. Note that $\Delta T \leq+2 \mathrm{~K}$ (inversion region) corresponds to $\Delta N>50 N$ units which is shown as a blue line in Fig. 9c. We can infer that if $\Delta N$ is less than $50 N$ units it corresponds to the noninversion region ( $\Delta N$ more than 50 may be inversion or otherwise). $\Delta N$ is thus a supportive parameter to $\Delta T$ in identifying inversion or noninversion. Because of its larger dynamic range, details of inversion have been identified in the $\Delta T$ and $\Delta N$ maps (figure not shown).

It is well known that COSMIC satellites are able to provide $N$ profiles directly. The spatial and temporal sampling of COSMIC at any particular region are, however, very meager. The comparison map of $\Delta N$ from IASI and $\Delta N$ from COSMIC combined for a long break spell from 30 July to $11 \mathrm{Au}-$ gust 2009 has been studied. This long period accumulation of data was necessary to have sufficient data points from COSMIC to cover the entire AS. One can see $\Delta N$ values above $50 \mathrm{~N}$ units (inversion region) covering the entire AS corresponding to $\Delta T$ values being below $2 \mathrm{~K}$ (shown by IASI, figure not shown). Over the AS region, $\Delta N$ observed for all 5 years of our study were combined to produce the frequency distribution of $\Delta N$ over the western AS $\left(5-25^{\circ} \mathrm{N}, 56-65^{\circ} \mathrm{E}\right.$, excluding land) and eastern AS (5-25 $\mathrm{N}, 66-75^{\circ} \mathrm{E}$, excluding land) and is shown in Fig. 10. Over the WAS, 712 cases and over the EAS, 547 cases show $\Delta N>50 N$ units (which may be supportive to inversion). A difference of about $10 \mathrm{~N}$ units can be noticed, with the WAS having higher $\Delta N$ values.

\section{Summary and conclusions}

Low-level MI characteristics, which usually occur below $700 \mathrm{hPa}$ over the AS during the southwest monsoon months, have been identified directly from operational satellite tem-

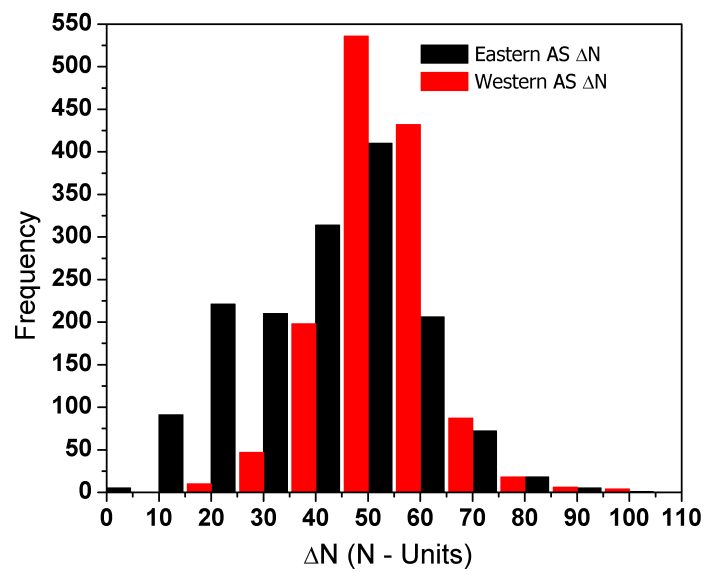

Figure 10. Frequency of $\Delta N$ observed in the western AS and eastern AS during monsoon season of the years 2009-2013 for various ranges of $\Delta N$ by COSMIC. The western AS shows higher values, meaning inversion is present.

perature retrievals. Here, for the first time, we have shown cases of direct and unambiguous delineation of MI from the satellite temperature and water vapour retrieval observations. We have used 5 years (2009-2013) of data of two different satellite sounder instruments (mainly from IASI, and for intercomparison, AIRS) along with ERA-Interim reanalysis data to delineate the characteristics of MI over the AS. Their percentage occurrence, base height and strength have been studied. For supporting our findings, we also compare with the campaign of MONEX 1979 in situ measurements over the AS. The main findings obtained from the observational study are summarized in the following:

1. Percentage occurrences of MI over the WAS (up to $\left.\sim 65^{\circ} \mathrm{E}\right)$ are $\sim 60-70 \%$ and are always higher and stronger than over the EAS. WAS $\Delta T$ values are $\sim 2 \mathrm{~K}$ less than those over the EAS.

2. MI is stronger during poor monsoon year (2009) and occurs on more occasions in the WAS during break spells (30 July-11 August 2009). Whether this is true or not for all poor monsoon years need to be checked with more years of data.

3. These features are also observed in the ERA-Interim data, but are restricted to some parts of the AS with more smoothed variability.

4. Intercomparison of IASI and AIRS profiles from the view of study of inversion suggests the differences do not warrant a mix of these two data sets for this study.

5. The refractivity data has only a supporting role to identify monsoon inversion regions.

Thus, MI seems to be a semipermanent feature of the Indian summer monsoon. It is suggested to include this feature 
also in future monsoon diagnostic and forecast studies. The diagnostics from ERA-Interim suggest the possibility of the AS MI forming during the middle of May, primarily due to subsidence mechanism and maintained later by the combined effects of advection and subsidence which are the subjects of our future study.

Acknowledgements. This work is a part of the INSAT-3D project, sponsored by the Indian Space Research Organization (ISRO), for which we are thankful to Space Applications Centre, Ahmadabad. We wish to thank C. M. Kishtawal, V. Sathiyamoorthy, S. Ghouse Basha, Jyotirmayee and Ranjit Thapa for discussions and for help in data processing aspects and help in using HPCC. The authors would like to thank ECMWF (http://apps.ecmwf.int/ datasets/data/interim-full-daily/levtype $=\mathrm{sfc} /$ ) for providing data of ERA-Interim, GESDISC (http://mirador.gsfc.nasa.gov/) for AIRS, NOAA (http://www.nsof.class.noaa.gov/ for IASI) for IASI through ftp. We also thank IMD for providing rainfall data over the Indian land mass.

Edited by: J. Kuttippurath

\section{References}

Anthes, R. A., Bernhardt, P. A., Chen, Y., Cucurull, L., Dymond, K. F., Ector, D., Healy, S. B., Ho, S. P., Hunt, D. C., and Kuo, Y. H.: The COSMIC/FORMOSAT-3 mission: Early results, B. Am. Meteorol. Soc., 89, 1-21, doi:10.1175/BAMS-89-3-313, 2008.

Basha, G. and Ratnam, M. V.: Identification of atmospheric boundary layer height over a tropicalstation using high-resolution radiosonde refractivity profiles: Comparison with GPS radio occultation measurements, J. Geophys. Res., 114, D16101, doi:10.1029/2008JD011692, 2009.

Bhat, G. S.: The Indian drought of 2002: a sub-seasonal phenomenon, Q. J. Roy. Meteor. Soc., 32, 2583-2602, 2006.

Clerbaux, C., Hadji-Lazaro, J., Turquety, S., George, M., Coheur, P. F., Hurtmans, D., Wespes, C., Herbin, H., Blumstein, D., and Tourniers, B.: The IASI/MetOp 1 Mission: First observations and highlights of its potential contribution to GMES 2, Space Research Today, 168, 19-24, doi:10.1016/S0045-8732(07)80046-5, 2007.

Clerbaux, C., Boynard, A., Clarisse, L., George, M., Hadji-Lazaro, J., Herbin, H., Hurtmans, D., Pommier, M., Razavi, A., Turquety, S., Wespes, C., and Coheur, P.-F.: Monitoring of atmospheric composition using the thermal infrared IASI/MetOp sounder, Atmos. Chem. Phys., 9, 6041-6054, doi:10.5194/acp-9-6041-2009, 2009.

Colon, J. A.: On interactions between the Southwest Monsoon Current and the Sea Surface over the Arabian Sea, Indian J. Met. Geophys., 15, 183-200, 1964.

Das, P. K.: The Monsoons, Nation Book Trust, New Delhi, India, ISBN 978-81-237-1123-2, p. 193, 2002.

Dwivedi, S., Sathiyamoorthy, V., Narayanan, M. S., and Rao, D. N.: A Study on the Lower Tropospheric Thermal Inversion Over the Arabian Sea Using Radiosonde and IASI Data, IEEE J. Sel. Top. Appl., 9, 490-495, doi:10.1109/JSTARS.2015.2506759, 2016.
Gadgil, S. and Joseph, P. V.: On breaks of the Indian monsoon, P. Indian Acad. Sci., 112, 529-558, 2003.

Kidder, S. Q. and Haar, T. H. V.: Satellite Meteorology - An Introduction, Acedemic press inc., California, USA, ISBN 0-12406430-2, p. 199, 1995.

Kripalani, R. H., Kulkarni, S. A., Sabade, S., Revadekar, J. V., Patwardhan, S. K., and Kulkarni, J. R.: Intra-seasonal oscillations during monsoon 2002 and 2003, Curr. Sci. India, 87, 325-331, 2004.

Kursinski, E. R., Hajj, G. A., Schofield, J. T., Linfield, R. P., and Hardy, K. R.: Observing Earth's atmosphere with radio occultation measurements using the Global Positioning System, J. Geophys. Res., 102, 23429-23466, doi:10.1029/97JD01569, 1997.

Kwon, E. H., Sohn, B. J., William, L., and Smith, J. L.: Validating IASI temperature and moisture sounding retrievals over East Asia using radiosonde observations, J. Atmos. Oceanic Tech., 29, 1250-1262, doi:10.1175/JTECH-D-11-00078.1, 2012.

Lambrigtsen, B. H.: Calibration of the AIRS microwave instruments, IEEE T. Geosci. Remote, 41, 369-378, 2003.

Narayanan, M. S. and Rao, B. M.: Detection of monsoon inversion by TIROS-N satellite, Nature, 294, 546-548, 1981.

Narayanan, M. S. and Rao, B. M.: Stratification and convection over Arabian Sea during monsoon 1979 from satellite data, P. Indian A. S.-Earth, 98, 339-352, 1989.

Narayanan, M. S., Rao, B. M., Shah, S., Prasad, V. S., and Bhat, G. S.: Role of atmospheric stability over the Arabian Sea and the unprecedented failure of monsoon 2002, Curr. Sci. India, 86, 7, 938-947, 2004.

Rajeevan, M. and Bhate, J.: A high resolution daily gridded rainfall data set (1971-2005) for mesoscale meteorological studies, Curr. Sci. India, 96, 558-562, 2009.

Rajeevan, M., Bhate, J., Kale, J. D., and Lal, B.: High resolution daily gridded rainfall data for the Indian region: Analysis of break and active monsoon spells, Curr. Sci. India, 91, 296-306, 2006.

Ramage, C. S.: The Summer Atmospheric Circulation over the Arabian Sea, J. Atmos. Sci., 23, 144-150, 1966.

Roja Raman, M., Venkat Ratnam, M., Rajeevan, M., Jagannadha Rao, V. V. M., and Vijaya Bhaskara Rao, S.: Intriguing aspects of monsoon low level jet over peninsular India revealed by high-resolution GPS radiosonde observations, J. Atmos. Sci., 68, 1413-1423, doi:10.1175/2011JAS3611.1, 2011.

Sathiyamoorthy, V., Mahesh, C., Gopalan, K., Prakash, S., Shukla, B. P., and Mathur, A. K.: Characteristics of low clouds over the Arabian Sea, J. Geophys. Res., 118, 13489-13503, 2013.

Schlüssel, P., Hultberg, T. H., Philipps, P. L., August, T., and Calbet, X.: The operational IASI level 2 processor, Adv. Space Res., 36, 982-988, doi:10.1016/j.asr.2005.03.008, 2005.

Simmons, A. J. and Hollingsworth, A.: Some aspects of the improvement in skill of numerical prediction, Q. J. Roy. Meteor. Soc., 128, 647-677, 2002.

Simmons, A. J., Uppala, S., Dee, D., and Kobayashi, S.: ERAInterim: New ECMWF reanalysis products from 1989 onwards. ECMWF Newsletter, 110, Reading, UK, 25-35, 2007.

Simon, B., Rahman, S. H., Joshi, P. C., and Desai, P. S.: Shifting of the convective heat source over the Indian Ocean region in relation to performance of monsoon: a satellite perspective, Int. J. Remote Sens., 29, 387-397, doi:10.1080/01431160701271966, 2007. 
Smith, N., Smith Sr., W. L., Weisz, E., and Revercomb, H. E.: AIRS, IASI, and CrIS Retrieval Records at Climate Scales: An Investigation into the Propagation of Systematic Uncertainty, Am. Meteorol. Soc., 54, 1565-1481, doi:10.1175/JAMC-D-14-0299.1, 2015.

Susskind, J., Barnet, C. D., and Blaisdell, J. M.: Retrieval of atmospheric and surface parameters from AIRS/AMSU/HSB data in the presence of clouds, IEEE T. Geosci. Remote, 41, 390-409, 2003.
Schlatter, T. W.: An assessment of operational TIROS-N temperature retrievals over the United States, Mon. Weather Rev., 109, 110-119, 1981.

Wallace, J. M. and Hobbs, P. V.: International Geophysics series: Atmospheric Science - An Introductory Survey, Second Edition, 92, ISBN 13:978-0-12-732951-2, Academic press, California, USA, p. 391, 2006.

WMO: The Monsoon Experiment, GARP Publication series no. 18, Geneva, Switzerland, 1976. 